\title{
Ferramentas e métodos de geração de ideias: aplicação da metodologia sinética
}

\author{
Helena do Socorro Campos da Rocha \\ Universidade Federal do Pará (UFPA) \\ (helenacefetpa@yahoo.com.br)
}

Adriana da Conceição Barros do Rosário

Universidade Federal do Pará (UFPA)

(adriana.silvabarros@yahoo.com.br)

\section{Rosa Maria Siqueira de Carvalho Rodrigues}

Universidade Federal do Pará (UFPA)

(rosaametistaufpa@bol.com.br)

\begin{abstract}
Resumo: Trata-se de um relato de experiência ocorrido na Turma do Mestrado Profissional em Ensino do Programa de Pós-Graduação Criatividade e Inovação em Metodologias de Ensino Superior (PPGCIMES), da Universidade Federal do Pará (UFPA), na disciplina Criatividade, acerca da aplicabilidade da ferramenta de geração de ideias Sinética. Após a realização de uma curadoria acerca dos problemas enfrentados pelos discentes da UFPA, um dentre tantos ganhou destaque pelo fato de estar diretamente ligado à continuidade do ciclo acadêmico. A problemática gira em torno das alunas universitárias que se tornam mães enquanto estão cursando a graduação e enfrentam inúmeras dificuldades para continuar a estudar, tais como: ausência de creche na universidade, não executarem as atividades por terem que cuidar do bebê em sala de aula, dentre outros. O objetivo da experiência foi propor algumas soluções para enfrentar dificuldades de universitárias que se tornaram mães durante o curso de graduação utilizando a metodologia Sinética. Partimos do pressuposto de que a Sinética, enquanto ferramenta de solução de problemas, é uma metodologia de trabalho eficiente na utilização em sala de aula em situações reais, além de ser grande fomentadora da criatividade. O objetivo geral foi apresentar a metodologia e os recursos utilizados para trabalhar a compreensão da turma acerca da ferramenta Sinética. Conclui-se que o texto escolhido para leitura da turma (PAES, 2013), a metodologia ativa Sala de Aula Invertida, as dinâmicas trabalhadas (Corrida Sinética e Forca Analógica), a estratégia de utilização de produção de Mapas Mentais pelas equipes e a dinâmica da Síntese das Analogias contribuíram significativamente para a compreensão da Sinética enquanto ferramenta de geração de ideias com vistas a solucionar problemas.
\end{abstract}

Palavras-chave: Criatividade; Sinética; Sala de aula invertida.

\section{Tools and idea generating methods: application of the sinética methodology}

Abstract: This is an experience report that took place in the Master's Degree Program in Teaching of the Postgraduate Program Creativity and Innovation in Higher Education Methodologies (PPGCIMES), Federal University of Pará (UFPA), in the discipline Creativity about the Applicability of Tool for the Generation of Sinética Ideas. After conducting a curation about the problems faced by UFPA students, one among them was highlighted because it was directly linked to the continuity of the academic cycle. The problem revolves around university students who become mothers while they are in undergraduate and face numerous difficulties to continue studying, such as: absence of day care at university, do not perform activities because they have to take care of the baby in the classroom, among others. The objective of the experiment was to propose some solutions to face difficulties of university students who became mothers during the undergraduate course using the Sinética methodology. We start from the assumption that Sinética, as a problem solving tool, is an efficient working methodology in classroom use in real situations, besides being a great promoter of creativity. The general objective was to present the methodology and resources used to work the group's understanding of the Sinética tool. It is concluded that: the text chosen for class reading (PAES, 2013) through the active methodology Classroom Inverted, the dynamics worked (Synthetic Race and Analogic Force), the strategy of using Mental Maps production by teams and dynamics of the Synthesis of Analogies contributed significantly to the understanding of Sinética as a tool for generating ideas in order to solve problems. 
Keywords: Creativity; Sinética; Inverted classroom.

\section{INTRODUÇÃO}

Durante uma das atividades, no Mestrado Profissional em Ensino, ofertado pelo Programa de Pós-Graduação Criatividade e Inovação em Metodologias de Ensino Superior (PPGCIMES) da Universidade Federal do Pará (UFPA), na disciplina denominada "Criatividade", foi proposto que, em equipes, os mestrandos desenvolvessem um projeto que contemplasse ferramentas e métodos de geração de ideias para solucionar problemas.

A equipe foi desafiada a pesquisar, estudar e entender a Sinética, que tem como objetivo evitar percursos tradicionais e soluções imediatas e conhecidas, por meio de dois tipos de mecanismos mentais: "transformar o estranho em familiar" e "transformar o familiar em estranho", e, dessa forma, poder aplicar o estudo do método em uma aula com duração de $4 \mathrm{~h}$. A princípio, um problema deveria ser escolhido para aplicabilidade da ferramenta de geração de ideias - Sinética, como forma de apresentar possíveis soluções. Após uma curadoria realizada pela equipe, em uma sessão de brainstorming, dinâmica de grupo usada como uma técnica para resolver problemas específicos, desenvolver novas ideias, projetos e juntar informação que estimule o pensamento criativo, buscou-se elencar algumas situações enfrentadas pelos discentes das graduações na UFPA, optando pela problemática das alunas universitárias que se tornam mães enquanto estão cursando a graduação e passam por dificuldades para continuar os estudos, por ser a questão mais recorrente nos textos lidos durante a realização do processo de curadoria.

Partimos do pressuposto de que a Sinética, enquanto ferramenta de solução de problemas, é uma metodologia eficiente na utilização em sala de aula em situações reais, além de ser grande fomentadora da criatividade.

O objetivo aqui é apresentar a metodologia e os recursos utilizados para trabalhar a compreensão da turma acerca da ferramenta Sinética. O texto está dividido em cinco partes, a saber: a fundamentação teórica; a demonstração do passo a passo da aula com as dinâmicas aplicadas; a apresentação do problema e da metodologia usada para sensibilizar a turma; as estratégias de solução do problema através de mapas mentais e a apresentação da síntese das analogias. $\mathrm{O}$ 
quinto e último momento foi destinado à escolha de uma das estratégias e ocorreu o aperfeiçoamento da mesma para resolver a questão problema.

\section{FUNDAMENTAÇÃO TEÓRICA}

\subsection{Criatividade}

Neste texto, entendemos a criatividade como o processo teórico que gera a ideia, em que o indivíduo planeja estrategicamente a efetivação de um projeto. No entanto, para que essa ideia ganhe forma, se materialize e entre no plano da implementação passamos para uma nova etapa denominada inovação. Portanto, inovação e criatividade são duas categorias diferentes, mas complementares (FILION; DOLABELA, 2011).

Em Alencar (1997), temos que a criatividade está relacionada com os processos de pensamento que interagem com a imaginação, o insight, a invenção, a intuição, a inspiração, a iluminação e a originalidade. Muito distante de apenas gerar ideias, a criatividade configura-se em

(...) saber utilizar a informação disponível, em tomar decisões, em ir além do que foi aprendido, sobretudo, em saber aproveitar qualquer estímulo do meio para gerar alternativas na solução de problemas e na busca da qualidade de vida. (TORRE, 2005, p. 34)

O autor destaca quatro momentos do processo criativo: a) a consciência da criatividade como bem social; b) a contextualização e problematização; c) a disseminação de propostas criativas; e d) a avaliação dessas práticas. Depreendese então que, a criatividade se faz na relação com o outro e tem como ponto de partida as experiências e conhecimentos anteriores. Logo, o processo criativo não se dá no plano da espontaneidade, como se fosse por autogênese. A criatividade acontece a partir de uma aproximação com as ideias anteriores que depois são ressignificadas.

Essa ressignificação se dá nas relações interpessoais, no convívio com o outro e, dessa forma Alencar e Fleith (2003, p. 4-5) sugerem alternativas para que a criatividade seja estimulada 
independência enfatizando valores ao invés de regras; (c) ressaltar as realizações ao invés de notas ou prêmios; (d) enfatizar o prazer no ato de aprender; (d) evitar situações de competição; (e) expor os indivíduos a experiências que possam estimular sua criatividade; (f) encorajar comportamentos de questionamento e curiosidade; (g) usar feedback informativo; (h) dar aos indivíduos opções de escolha; e (i) apresentar pessoas criativas como modelos.

Esse pensamento corrobora com Torre (2005, p. 59), quando postula que as variáveis do contexto sócio histórico cultural interferem na produção criativa e podem ou não favorecer a materialização do comportamento criativo, pois "a mente reprodutora repete 0 adquirido, a mente criativa transforma a informação de forma pessoal". Assim sendo, o pensamento criativo se caracteriza especialmente pela originalidade da ideia que consiste em ver o mundo de maneira diferente, ou seja, observar o que todos observam, mas ver o que ninguém percebe e assim pensar o que ainda ninguém pensou. Mas, primeiramente faz-se necessário reconhecer que todos possuem um potencial para a criatividade, portanto, que qualquer pessoa pode ser criativa desde que seja exposta a esses estímulos.

De acordo com Alencar (1997), observa-se que em diversas culturas a criatividade é estimulada, porém de modo geral, a criatividade é mais reprimida do que de fato incentivada, visto que muitos professores têm dificuldades em corroborar para que seus alunos desenvolvam as habilidades do pensamento criativo e adquiram novas competências pedagógicas necessárias para o desenvolvimento da aprendizagem. Sabe-se que um processo criativo e inovador não está somente atrelado e condicionado à criação de algo, mas como também ao aperfeiçoamento daquilo que se pretende inovar. Assim sendo, compreende-se que a criatividade é parte fundamental para a educação, porque é reconhecida como uma habilidade prática, que pode ser ensinada e que todos podem alcançar. O processo criativo materializa-se a partir do emprego de técnicas e métodos com etapas específicas (preparação, incubação, iluminação e elaboração) culminando em produto criativo.

Torre (1996) sustenta que cada um de nós é um "diamante em bruto" precisando passar pelo processo de polimento e limpeza através da prática criativa que vai levar em conta o potencial pessoal, o contexto e o reconhecimento social.

Kneller (1978 apud ALENCAR, 1997) postula que a criatividade está associada às capacidades produtivas inerentes ao pensamento convergente e divergente. O pensamento convergente tem como característica uma única direção, buscando uma resposta única, uma solução convencional. Já o pensamento divergente desloca-se em diversas direções, em busca de ideias variadas sobre um 
objeto ou resolver problemas fora dos padrões tradicionais. Logo, o pensamento divergente caminha lado a lado com a criatividade, pela inovação, rompendo as barreiras com a rotina, com o convencional em busca de possibilidades para a solução de um problema. Nesta perspectiva não se considera apenas uma única resposta como certa para se resolver os desafios.

Atualmente, o professor precisa dispor de diversas estratégias de ensino que utilizem novas abordagens para alimentar o processo criativo e inovador dos alunos. Dessa maneira a criatividade pode ser aplicada na procura de soluções para diferentes problemas, sob a forma de produtos, serviços ou processos.

Porém, para que isso ocorra o professor pode utilizar várias ferramentas e métodos de geração de ideias que busquem incentivar o processo criativo em seus alunos, os quais são essenciais para a maioria das situações relacionadas à melhoria e inovação de produtos, serviços e processos. Essas técnicas podem ser utilizadas para a geração de ideias num sentido macro ou ter uma função específica que responda de imediato ao que pretende ser desenvolvido no decorrer do processo de ensino e aprendizagem.

Neste sentido, podem ser encontradas técnicas que sirvam para diferentes fins, tais como: compreender o problema, gerar ideias para resolver o problema detectado, selecionar dentre as ideias já existentes a mais eficaz para solucionar o problema e planejar atividades para colocar essas técnicas em prática.

Acima de tudo, é essencial que se desenvolva uma cultura organizacional que propicie a criatividade e que incentive os alunos a usar as suas habilidades através de técnicas de geração de ideias. Faz-se necessário para isso, ensinar e estimular a criatividade de forma coletiva, o que implica necessariamente na aplicação prática de várias técnicas, entre as quais o Brainstorming, Mapas Mentais, Scamper, Matriz Morfológica e a Sinética. Sendo essa última o objeto de estudo deste artigo por ser âncora do pensamento criativo no desenvolvimento de metáforas e analogias, transformando o familiar em estranho e vice-versa.

\subsection{Sinética}

O termo sinética tem sua raiz etimológica no grego e significa juntar elementos diferentes, aparentemente não relacionados entre si. A Sinética (Synectics) foi desenvolvida por Gordon em 1957, como um aperfeiçoamento do método brainstorming, com o objetivo de evitar percursos tradicionais e soluções 
imediatas e conhecidas, e baseia-se em dois tipos de mecanismos mentais: "transformar o estranho em familiar" e "transformar o familiar em estranho".

Para a transformação do estranho (desconhecido ou complexo) em algo familiar e compreensível, são utilizados os seguintes procedimentos: Análise (decomposição em partes); Síntese (redução em esquemas: mapas ou diagramas fomentam a simplificação); Generalização (relacionar com situações concretas e conhecidas). No entanto, este é um processo conservador e natural do ser humano que leva a soluções tradicionais. (PAES, 2013).

Em busca de soluções inovadoras, a Sinética propõe o rompimento dessa tendência conservadora, percorrendo o caminho inverso, transformando o familiar em estranho e para tanto, recorre a quatro tipos de analogias para encontrar perspectivas pouco comuns (GORDON, 1961 apud PAES, 2013):

a) Analogia pessoal - a pessoa coloca-se no lugar do processo, produto, mecanismo que pretende desenvolver a partir da identificação pessoal do indivíduo com os elementos do problema, estabelecendo relações a partir do repertório e das características da pessoa;

b) Analogia direta - são feitas comparações com fatos reais, tecnologias ou conhecimentos semelhantes e ocorre através da relação de fatos e conhecimentos paralelos, transpondo conhecimentos de um domínio para outro;

c) Analogia simbólica - utiliza-se de imagens objetivas e impessoais para descrever o problema através de associações imediatas com símbolos, recorrendo a imagens mentais;

d) Analogia fantasiosa - foge às leis e normas estabelecidas. Esta analogia apela para a irracionalidade, fugindo de regras convencionais. É uma fuga consciente para um mundo fantasioso, quando as associações são criadas de forma fantasiosa, sem regras ou preocupação com a realidade.

A ideia básica consiste em definir a problemática na qual se deseja inovar, deixando claro quais são os seus elementos para, então, realizar articulações com as situações análogas, dispositivos ou qualquer coisa que possa ser associada com um ou mais dos elementos do problema, buscando a solução mais viável.

A Sinética enquanto ferramenta geradora de ideias tem como objetivos: a) Permitir que o indivíduo perceba a realidade de forma não corriqueira, tornando possível que um grupo de pessoas faça emergir, do nível inconsciente, várias ideias visando à solução do problema proposto; b) Aumentar a consciência e os 
mecanismos que podem ser utilizados para chegar a soluções novas de um problema; c) Obter respostas de qualidade e não de quantidade.

Uma das características específicas dessa ferramenta de geração de ideias é que o grupo participante precisa ser composto por especialistas em cada aspecto do problema a ser resolvido. O ponto fraco é que a criatividade fica reduzida em relação ao brainstorming, porque os participantes permanecem focados em suas especialidades e nas experiências de que dispõem. No entanto há um grande ganho em qualidade e objetividade.

\section{A APLICAÇÃO DA FERRAMENTA SINÉTICA}

A partir do problema definido e, partindo do pressuposto de que o ambiente também serve de elemento estimulador e facilitador em relação ao trabalho criativo, a metodologia foi desenvolvida da seguinte forma: primeiramente, dividiu-se a turma em quatro grupos, sendo dois desses grupos com quatro integrantes cada um e os outros dois, com três integrantes cada, usando o critério de não pertencerem à mesma área do conhecimento, sendo que cada equipe representou uma das analogias aplicadas à Sinética (analogia direta, analogia simbólica, analogia fantasiosa e analogia pessoal); a sala de aula foi inteiramente organizada e padronizada de acordo com a temática escolhida, a qual remetia à primeira infância; os alunos receberam crachás em forma de chupetas nas cores verde limão, marrom, verde bebê e vinho, cada uma correspondente ao grupo pertencente,' conforme as analogias.

Numa sessão de Sinética, estas quatro diferentes analogias ocorrem simultaneamente, não sendo possível separá-las. No entanto, nesta experiência, para efeito didático, os grupos, a princípio, trabalharam apenas em uma das analogias, buscando possíveis soluções para o problema apresentado. 
Figura 1: Ambientação do espaço da sala de aula

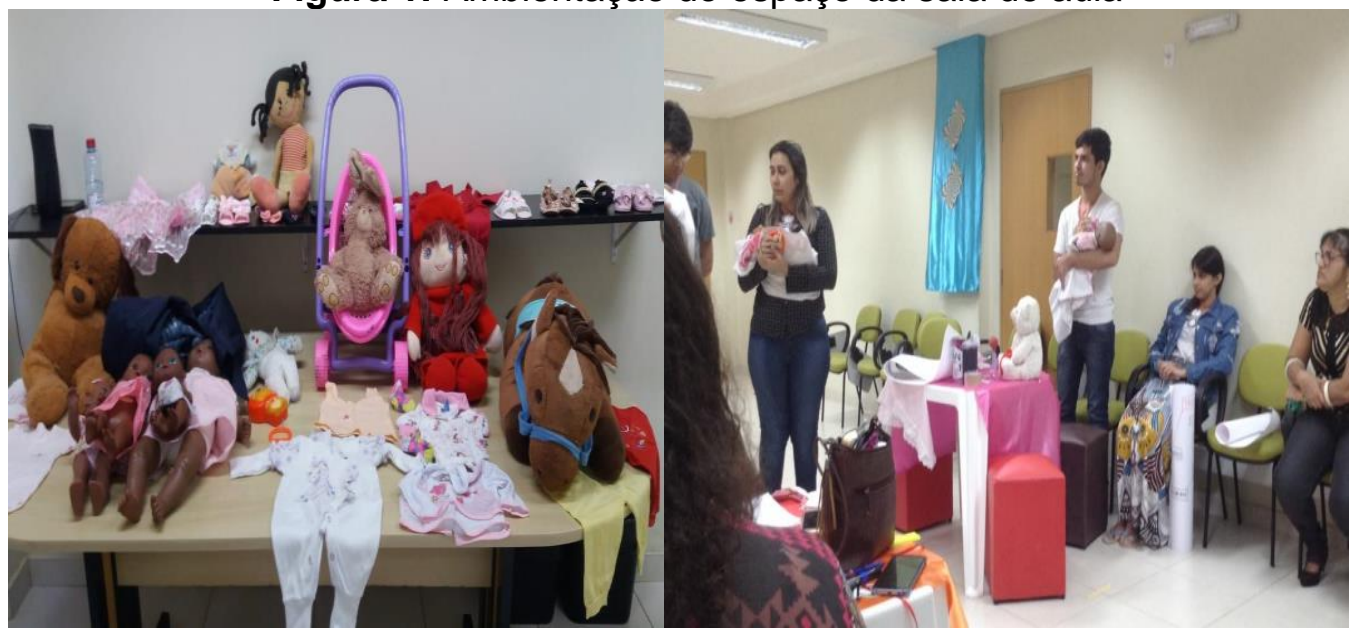

Fonte: Arquivo Equipe Synectics. Junho, 2018.

Uma das integrantes de cada grupo foi escolhida para carregar consigo, durante todo o decorrer da aula uma boneca, que deveria ser cuidada como se fosse uma criança, e realizar todas as atividades sem deixá-la nem por um minuto.

Em meio às atividades, um efeito sonoro de choro de bebê era acionado, obrigando quem estava com a boneca a tomar os cuidados necessários para que parasse de chorar e a aluna/mãe continuasse sua tarefa.

A metodologia ativa empregada foi uma adaptação da Sala de Aula Invertida que

busca o protagonismo dos aprendizes e opera a partir do pressuposto de que o tratamento dos conteúdos de aprendizagem ocorre principalmente fora da sala de aula e deve ser uma tarefa compartilhada entre os alunos em sala de aula com acompanhamento docente em vez do trabalho exclusivo do professor. (SILVA, 2015, p. 6)

No segundo momento, as quatro equipes participaram da dinâmica permeada pela Gamificação chamada Corrida Sinética, a fim de consolidar conceitos através de 24 perguntas: o líder girava a roleta para tirar uma carta com a pergunta da sua equipe, que tinha um minuto para responder. Caso não soubesse a resposta, passava a vez. A carta não respondida retornava para o monte inicial. Havia duas cartas surpresa: o Coringa sinético maquiavélico, que fazia o componente da equipe retornar uma casa, e o Coringa sinético criativo, que permitia avançar uma casa. Ganhava a equipe que cruzasse a linha de chegada primeiro. 
Figura 2: Corrida Sinética

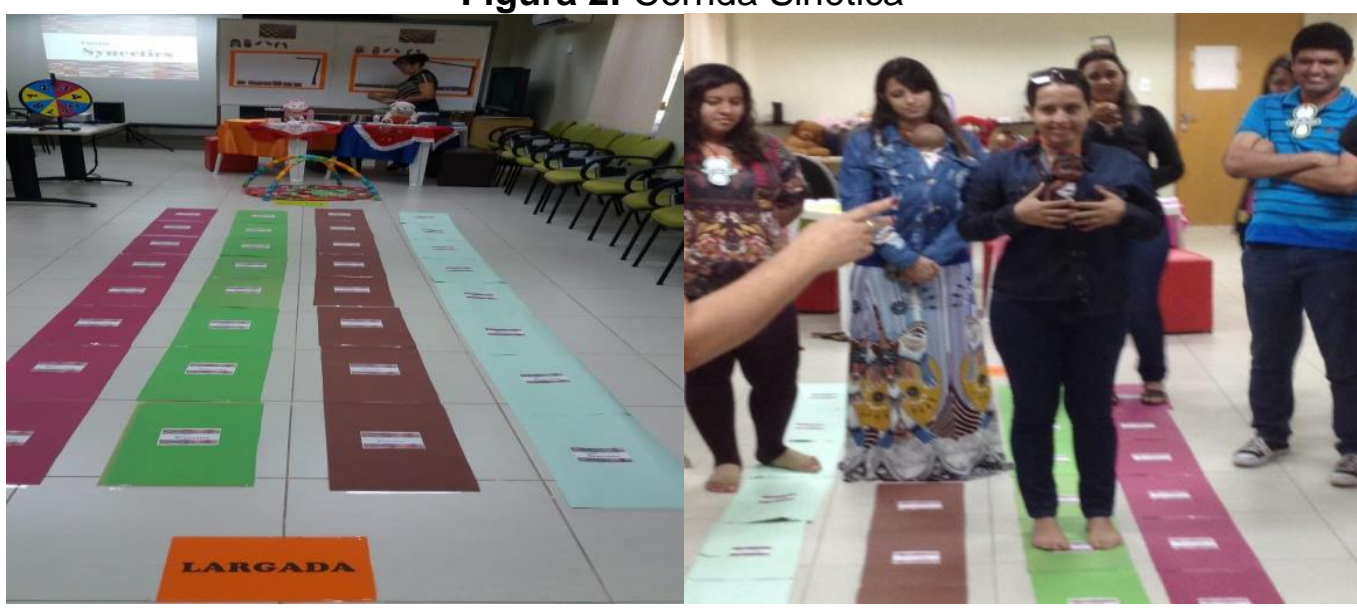

Fonte: Arquivo Equipe Synectics. Junho, 2018.

Em seguida, ocorreu a dinâmica intitulada Forca Analógica, sendo que nesse momento a turma foi dividida em duas equipes somente, as quais eram formadas por duas das quatro analogias representativas da Sinética juntas: foram montadas duas forcas, uma para cada equipe. Cada equipe tinha um minuto para indicar uma letra para compor uma palavra; após lido o conceito, se a letra indicada não estivesse correta, era acrescentada uma parte da boneca na forca. Ganhava a equipe que completasse a palavra corretamente, levando automaticamente a boneca da outra equipe a ser enforcada.

\section{O PROBLEMA}

A segunda fase da aula consistiu na apresentação de dois vídeos à turma: o primeiro, de uma campanha publicitária do carro SpaceFox, veiculada em 2014, acerca da Sinética; o segundo, de uma reportagem do G1, veiculada em 2017, intitulada "Mães universitárias enfrentam rotina de dificuldades para estudar na maior universidade do Norte, a UFPA".

O problema selecionado durante as reuniões da equipe Synectics justificou-se por ser considerado de grande relevância social, uma vez que ser mãe e estudante pode levar muitas jovens, por falta de apoio e condições financeiras, a desistirem de estudar, elevando o número de evasão nos cursos de graduação da UFPA. 


\section{ESTRATÉGIAS DAS EQUIPES}

$\mathrm{Na}$ terceira fase da aula, as quatro equipes participaram do momento de geração de ideias, sendo que, a partir das discussões, cada uma deveria construir um mapa mental da situação problema apresentada, levando em consideração, para isso, a ferramenta Sinética e suas analogias: analogia direta, analogia simbólica, analogia fantasiosa e analogia pessoal. Os mapas mentais produzidos podem ser visualizados na Figura 3:

Figura 3:Mapas Mentais dos Grupos Analogia Direta, Analogia Fantasiosa, Analogia Pessoal e Analogia Simbólica

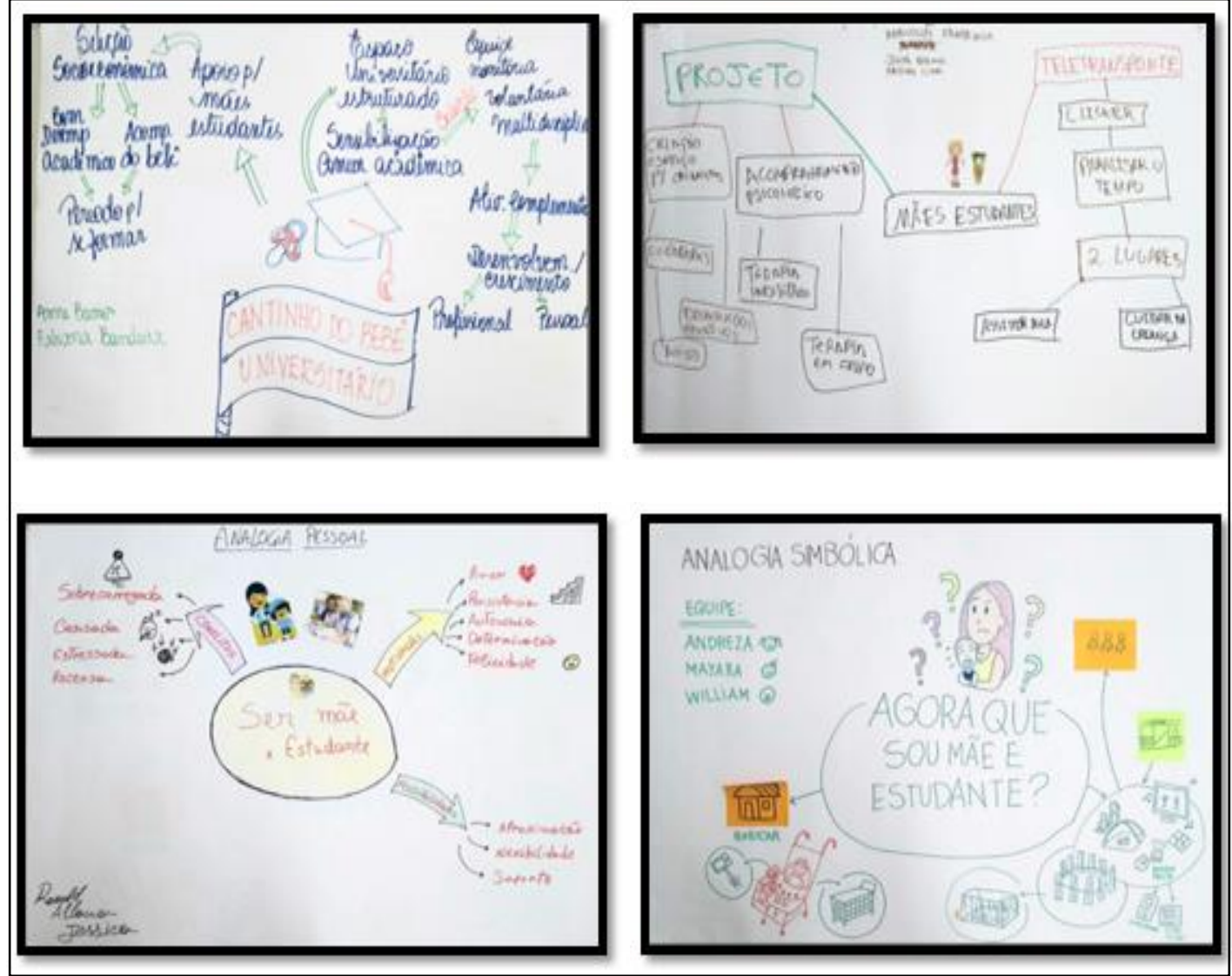

Fonte: Arquivo Equipe Synectics. Junho, 2018.

A equipe da analogia direta apontou como resolução do problema a criação do Cantinho do Bebê, para dar assistência profissional capacitada, porém voluntária, às alunas/mães e aos bebês; já a equipe de analogia fantasiosa pensou em um teletransporte para facilitar a vida dessas mães universitárias; enquanto que a equipe da analogia pessoal indicou um acompanhamento psicológico às alunas/mães; e, por fim, a equipe da analogia simbólica sugeriu a criação de objetos que facilitassem a vida dessas jovens mães. 
Nessa busca pela solução da problemática através da ferramenta Sinética, alguns fatores influenciaram significativamente as propostas dos grupos: a heterogeneidade - através das diversidades, dos valores de cada componente; as percepções que os participantes têm de si mesmos e o clima de sala de aula, além do que, a grande maioria ainda não havia experienciado práticas escolares de cunho criativo em sua trajetória.

\section{SÍNTESE DAS ANALOGIAS}

Ao final da apresentação, as equipes foram desfeitas e neste momento fizemos uma dinâmica que remetia a um quadro chamado Porta da Esperança, do apresentador Silvio Santos, do canal televisivo SBT.

Figura 4: Mapa Mental da Síntese dos Mapas Mentais das Analogias.

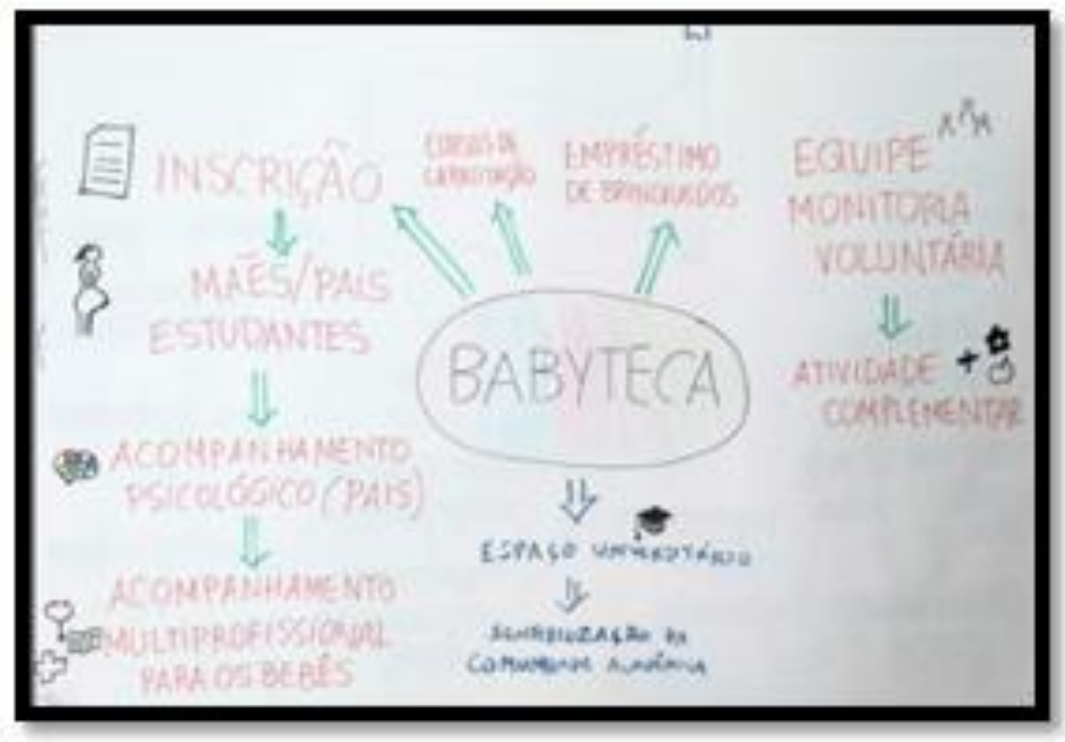

Fonte: Arquivo Equipe Synectics. Junho, 2018.

Cada participante dirigia-se ao cartaz que, em sua opinião, continha a proposta que mais se adequava para resolver a situação problema levantada, independentemente de ter sido aquele criado ou não pela sua equipe inicial, suprimindo assim a quantidade de respostas em detrimento da qualidade destas.

Partindo desse pressuposto, a maioria dos alunos optou pelo mapa mental elaborado pela equipe que representava a analogia direta e adaptaram o Cantinho do Bebê sugerido pela equipe, transformando-o em uma Babyteca, a qual deveria ser implementada em todos os Institutos da UFPA, com voluntários que realizariam um acompanhamento multiprofissional para os bebês e psicológico para os pais, 
oferecendo ainda cursos de capacitação para os pais, mediante um processo de seleção.

Segundo Lubart (2007, p. 16), "uma produção criativa não pode ser simplesmente uma resposta nova". Nesse sentido, a proposição da turma como solução para o problema remete-nos que as ideias criativas foram adaptadas para satisfazer às diferentes dificuldades ligadas ao contexto das alunas/mães dentro de uma Universidade que possui suas especificidades legais e burocráticas. Tal adaptação levou em conta os elementos da cultura, os mecanismos sociais que regulam a ação dos sujeitos e os mecanismos reguladores específicos de uma instituição de ensino.

\section{CONCLUSÃO}

Em síntese, a criatividade é uma habilidade humana de fazer circular e interagir um circuito de ideias capaz de promover qualidade, aperfeiçoamento e crescimento em determinado aspecto que necessita ser otimizado. No caso em questão, trata-se de uma problemática advinda de circunstâncias sociais que adentrou no meio acadêmico da UFPA e que necessita ser analisada para que não implique situações graves como a evasão das alunas/mães. Nesse sentido, a criatividade se molda de acordo com o ambiente em que está inserido. Em linhas gerais, isso significa que, dependendo do contexto e da situação problema, a criatividade será apresentada de maneira única e singular, mas as diferenças não impedirão sua ocorrência, e esta pode ser fomentada a partir de ferramentas de geração de ideias, tal qual a Sinética.

O texto escolhido para leitura da turma (PAES, 2013), as dinâmicas trabalhadas (Corrida Sinética e Forca Analógica), a estratégia de utilização de produção de Mapas Mentais pelas equipes e a dinâmica da Síntese das Analogias contribuíram significativamente para a compreensão da Sinética enquanto ferramenta de geração de ideias com vistas a solucionar um problema. A estratégia utilizada pela equipe Synectics para sensibilizar a turma para a problemática surtiu o efeito desejado na medida em que foi entregue uma boneca para ser cuidada a uma aluna de cada grupo e a simulação de choros obrigava a uma parada para os cuidados devidos. 
No momento de autoavaliação, surgiram questões instigantes acerca do papel da mulher atrelado à maternidade, culturalmente pela sociedade, e muitas variáveis em torno do problema, que extrapolam os muros da Universidade para sua solução, além das burocracias para uma implementação de saídas que se tornam paliativas e emergenciais.

A despeito do grande investimento na Formação de Professores, inicial e continuada, em cursos presenciais, semipresenciais e na modalidade Educação a Distância, o ambiente escolar apresenta fragilidades para equipar-se adequadamente com ferramentas que proporcionem apoio ao professor na difícil tarefa de contribuir significativamente na formação escolar dos cidadãos de forma criativa e inovadora. A Sinética é apenas uma dentre tantas ferramentas de incentivo a ideias inovadoras.

\section{REFERÊNCIAS}

ALENCAR, Eunice Lima Soriano. A gerência da criatividade. São Paulo: Makron Books, 1997.

ALENCAR, Eunice M. L. S. \& FLEITH, Denise de S. Contribuições teóricas recentes ao estudo da criatividade. Psicologia: Teoria e Prática. Jan-Abr 2003. Vol. 19 n.1. p.0108. Disponível em <http://www.scielo.br/pdf/ptp/v19n1/a02v19n1.pdf> Acesso em 10 ago. 2018.

DUNLOP, Sandy. Synectics: Creative Problem Solving, Self \& Society, v.9, n.2, p. 77-81, 1981.

FILION, Louis Jacques; DOLABELA, Fernando. Boa Ideia! E Agora?. São Paulo: Cultura Editores Associados, 2000.

LUBART, T. Psicologia da criatividade. Porto Alegre: Artmed, 2007.

PAES, Sandro. Conteúdos teóricos e práticos da disciplina de Comunicação Publicitária e Criatividade - CPC. Cursos técnicos de comunicação, Marketing, Relações Públicas e Publicidade. ESMGA 2012/2013

SILVA, Marco. Sala de aula invertida e sala de aula interativa: defesa da docência fortalecida. Livro de Resumos, Pernambuco, v. 1, p. 06, dez. 2015. Resumo do trabalho apresentado no $6^{\circ}$ Simpósio Hipertexto e Tecnologias na Educação $2^{\circ}$ Colóquio Internacional de Educação com Tecnologias.

TORRE, Saturnino de La. Dialogando com a criatividade. Tradução WIT Languagens. São Paulo: Madras, 2005. 